Studia Slavica Savariensia 2016. 1-2. 228-238

DOI: $10.17668 /$ SSS.2016.1-2.228

\author{
Józsa György Zoltán \\ (Budapest, Magyarország)
}

\title{
ЭДИП ИЛИ ТЕСЕЙ? ДВЕ АЛЬТЕРНАТИВЫ ИНДИВИДУАЦИИ В РОМАНЕ МЕРЕЖКОВСКОГО «ПЕТР И АЛЕКСЕЙ»
}

\begin{abstract}
In a comprehensive study on the mythologeme of Oedipus frequently occurring in fin-de-siècle European culture, the author ventures to scrutinise the explicit conflict between father and son in D. Merezhkovsky's novel Peter and Alexis. The mythical story rediscovered by Freud, not only stimulated the psychoanalytic models of psychosexual development and culture, but also fascinated Russian Symbolist's imagination. By relying on the theme of patricide the article juxtaposes the story of Oedipus with the story about Theseus. Loci in Merezhkovsky's theoretical essays offer interpretation of the cultural message coded in the myth.
\end{abstract}

Keywords: Merezhkovsky, the mythologeme of Oedipus, Theseus, Psychoanalysis, Principium Individuationis

Ход развертывающегося перед глазами читателя действия в последней части первой трилогии Мережковского, в романе Антихрист. Петр и Алексей сконцентрированно предзнаменуется первой главою, зловещей по содержанию. Названная Петербургской Венерой, она тематизирует главный конфликт через резкое сопоставление беседы царевича Алексея со стариком Докуниным о приближающемся конце света, предуготовляемом появлением на мировой арене антихриста, и, с другой стороны, - страшных событий дикого карнавального пиршества, устроенного в честь прибытия в новую российскую столицу с разрешения римского папы ящика, хранимого волей Петра Великого, из которого на новой родине воскреснет двухтысячелетняя статуя богини Венус, некогда украшавшая ватиканский сад.

Предложением такой резкой оппозиции между сектантским, старообрядческим, православным аскетизмом и вольной оргией, последующей за торжественной установкой статуи, автор прочерчивает штрихи сложных комплексов идей, которые не только включают оценку поворотного в российской истории пункта, сложившегося под воздействием деятельности Петра І-го и побуждающего читателя переосмыслить формирование и отношений между Востоком и Западом, и самую сущность данных понятий, но одновременно фиксируют главный тематический узел романа, воплощаемый в конфликте персонального 
разряда между отцом и сыном. Именно на почве этой психологической, если угодно - фрейдовой ситуации вырастают многочисленные и разнообразные линии систем «соответствий» (в подлинном, исконном, античном и символистском смысле этого термина), которые - наряду с теологическими, общественными, историческими импликациями, укореняющимися в двух типах мышления заглавных персонажей раскрывают через проецирование неисчислимых схем возможность для идентифицирования ряда их архетипичных сущностей. Сочетая сообразно своей писательской манере - подходы беллетриста, философа истории, историка религий, историка общественности и культуролога, Мережковский погружается в исследование связей глубинных слоев бессознательного человека и становления ментальности в свете архаического сознания человека. Персональное и универсальное в поэтике Мережковского суть разные уровни бытия, но движутся по единому закону. Сама трилогия уже ввиду своего названия представляет собой формулировку визионерства вселенского процесса с точки зрения смертного человека и «более осведомленного» автора, который способен улавливать моменты космического сцепления событий и их причинные закономерности.

Комплекс Эдипа ${ }^{1}$ прямо затрагивается уже благодаря аллюзии на парадигму Отцов и детей, закодированную в названии романа, не говоря о сознательном соблюдении традиции, ведь у предшественника Достоевского устойчивый лейтмотив патрицида прослеживается в романе Братья Карамазовы. Замыслом романа Мережковский несомненно во многом обязан и Достоевскому. Однако он развертывает тему, ставя патрицид в широкий историософский, эсхатологический и культурологический контекст, и благодаря трактовке становления индивидуальной психологии персонажа как результата духовной атмосферы эпохи, Мережковский, вечный сторонник ценностей индивида, симультанно освещает кардинальный конфликт индивида и коллектива. Лишь мимоходом заметим, что современник Андрей Белый, приводя в финале романа Петербург своего героя Николая Аблеухова, потенциального отцеубийцу к египетскому Сфинксу, одержим подобными идеями о переосмыслении мифа об Эдипе. Он формулирует собственный ответ на вопрос, поставленный Фрейдом: атрофия физического зрения героя у Белого является не как результат инцеста, а сигнализирует появление духовных органов, приспосабливающих героя к

\footnotetext{
1 Эдипов комплекс впервые изложен Фрейдом в работе Толкование сновидений (1899) в качестве аксиомы в теории сексуальной этиологии неврозов и психических процессов. Позже он станет главным ориентиром для формулировки психологии возникновения религий, конкретизированной в сочинении Тотем и табу (1913).
} 
пониманию символов иных миров ${ }^{2}$. Во избежание недоразумений, мы заранее заявляем, что предлагаемая нами рабочая гипотеза отнюдь не ставит перед собою цель доказать верифицируемость какой-либо контактологической связи между культурными моделями Фрейда и Мережковского ${ }^{3}$. Крупная проблематика многоплановой связи становления воззрений психоанализа и русской религиозной философии рубежа двух столетий широкомасштабно изучена в ряде статей и отдельных монографий ${ }^{4}$. Расхождение между моделями Мережковского и Фрейда очевидно заключается уже в том, что в соответствии с основным конфликтом романа отцеубийство равнозначно цареубийству, как и в случае древнегреческой мифологемы об Эдипе, где существенную роль играет мотив захвата власти. Недаром в изображении комплексной фигуры царевича доминирует религиозный аспект человека, в кругу людей «старого благочестия» он почитается как «человек богоискательный» (МЕРЕЖКОВСКИЙ 1990: 359). В подобном духе, небесполезно считаться с фактом, что во время работы над книгой Метаморфозы и символь либидо, этим важным документом, сигнализировавшим принципиальный отход от фрейдистской схемы чисто сексуализированного восприятия культуры, К.Г. Юнг восхищенный поклонник романов Мережковского «часто вспоминал» писателя согласно сообщению Э. Метнера, пациента Юнга и издателя его сочинений, посему следы учения об «эллинизме» ощутимы на некоторых страницах сочинения Юнга (МЕТНЕР 2013: 32-33) ${ }^{5}$. По сравнению с Фрейдом, Юнг значительно расширяет понятие либидо, его концепция во многом совпадает с символистскими учениями об Эросе. Далее, в качестве опорного пункта своей аналитической психологии Юнг развил и концепт principium individuationis, категорично отделяемый от понятия самолюбивого близорукого индивидуализма, т.е. теорию о процессе

${ }^{2}$ Об этом подробнее см. (SZILÁRD - JÓZSA 1996: 148-149).

3 Необходимо, однако, напомнить, что Фрейд в своем Леонардо да Винчи. Воспоминание детства (1910) восхваляет подход Мережковского к обрисовке душевного склада итальянского художника во второй части трилогии Христос $u$ антихрист.

${ }^{4}$ Об этом см. напр. (ЭТКИНД 1993). Если метод Фрейда вполне применим для расшифровки системы символов романа Ф. Сологуба Мелкий бес, то, в случае корпуса творений Мережковского, рискнем сказать, и фрейдизм и юнгианство имеют место как адекватные моделирующие системы, круг понятий которых корреспондирует типу мышления писателя. В таком контексте формула Достоевского о миссии России относительно судьбы европейской цивилизации как бы получает более широкую трактовку в статье Б. Гройса Россия как подсознание Запада, где данная парадигма чутко показана (ГРОЙС 1989).

5 О проблеме «Юнг и Мережковский» см. (РЫЧКОВ 2010: 202-203). Насчет детального изложения знакомства Юнга и Метнера см. кн. (LJUNGGREN 1994: 117-127). 
становления личности, осознания человеком своего высшего назначения. Сам концепт многосторонне освещается в разбросанных местах сочинений Юнга ${ }^{6}$. Точками соприкосновения между двумя мыслителями являются, среди прочих, их увлечение философией Ф. Ницше ${ }^{7}$ и затем отталкивания от нее, и стремления к разработке систем вселенских универсалий ${ }^{8}$.

Достоверные в психологическом плане портреты, нарисованные Мережковским, вместе с декорумом и с конструированием действия, обусловлены методом подробностного и скрупулезного восстановления компонентов полу-мифологического и полу-религиозного гармоничного всеединства, которые скреплены единым синкретизмом. Этот идеал, - как известно, - восходит к созерцанию Мережковским совершенства эллинской культуры. (Любопытно, что вопреки отрицательному в своей основе изображению Петра Великого, в силу его влечения к античному миру, романный персонаж ввиду своей полифоничной сущности парадоксально становится единомышленником Мережковского, поклонником и толкователем эллинизма: в своей речи о многобожии эллинов государь же в теософском ключе излагает обнаруживаемые им аналогичные факты религий, верований и суеверий (МЕРЕЖКОВСКИЙ 1990: 350-351). Вдобавок, импортированием телесного аспекта античности, Петр совершает попытку восстановить и интегрировать в русскую культуру утраченную историческим христианством телесность.)

${ }^{6}$ В трактате Парацельс как духовное явление он соотнесен с алхимическим понятием Apec, „natura prima rerum”: «Арес оказывается интуитивным понятием для выражения предсознательной творческой формообразующей силы, которая способна дать жизнь индивидуальным созданиям. Значит, Арес - более конкретная сила индивидуации 〈...». В трактате Дух Меркурий, где древо символизирует видимое воплощение становления «Самости» (,Selbst“), мы читаем: «в качестве жизненного принципа дерева он [дух] есть своего рода духовная квинтэссенция, абстрагированная от самого дерева, которую можно обозначить и как principium individuationis. Дерево в таком случае предстает внешним, зримым проявлением само-осушествления» (ЮНГ 1996: 109, 111).

7 Вопреки тому, что Фрейд, по-видимому, отрицает какого-либо воздействия философии Ницше на формирование своей теории психоанализа, согласно предположению Э. Джонса Фрейд уже ок. 1896 г. осознает, что ядро своих исследований содержится в известной формуле «Заратустры»: «Ибо достояние свое всегда хорошо спрятано от самого себя, и из всех сокровищ последним выкапывается всегда собственный клад 〈...〉.» Сходство учений Ницше и Фрейда прямо затрагивается Г. Заксом близким сотрудником Фрейда при совместном визите с Джонсом к сестре Ницше в 1911 г., во время Веймарского конгресса психоаналитиков (JONES 1963: 206-207, 276, ASSOUN 2002: 11-14)

${ }^{8}$ Об этом см. (ЛАВРОВ 2000: 11, 14). Тщательное описание влияния Ницше на Юнга дается в кн. (BISHOP 1995). 
Итак, мифический, сектантский подтексты произведения Мережковского способствуют тому, чтобы читатель постепенно открывал в себе способность активизировать эти остатки древнего сознания. Пережитки данного типа сознания наличествуют в речах и разговорах романных персонажей, русских сектантов, толкующих реалии действительности сквозь призму знакомых им сюжетов и закодированных в них символов. Сектанты еще хранят древний язык, сокровенный язык символов, недоступный современному «просвещенному» человеку. Последний может расшифровывать феномены действительности, оперируя лишь абстрагированными понятиями. Однако, ностальгический интерес к подобному методу интерпретации действительности ощутим и в кругу светского, нередко образованного, придворного сословия, изображаемого в романе: свой текст Мережковский нарочито снабжает целым списком атрибутированных отдельным персонажам произведений, как напр. Гамлет Шекспира (по Фрейду причины падения принца датского и героя Царя Эдипа одинаковы), любимое чтение придворной дамы фрейлины Арнгейм или Метаморфозы Овидия, переводимые тайным советником Толстым, воспринимаемые ими в качестве настольных книг по символогии. Данный жест включить истоки истолкования символов внушает мысль об интенции Мережковского гармонизировать замысел романа с теорией, изложенной им на страницах манифеста $O$ причинах упадка и о новых течениях современной русской литературы (1893). Согласно дефиниции, зафиксированной в этом трактате, символизм как воскресающее время от времени явление всегда присутствовал как в процессе развития европейских искусств, так и в сознании художников (МЕРЕЖКОВСКИЙ 1972: 246-247). Уточняем: на взгляд Мережковского сама сущность символистского типа искусства таится в возвращении к идеализму, в глубокой религиозности этого типа искусства.

На антагонизме отца и сына, осложненном мыслью царевича о захвате царской власти, базируется динамика действия. Постоянное присутствие отца в мыслях Алексея маркируется уже в первом диалоге романа, сын практически не способен от него оторваться. Символичность первой в романе встречи родителя и отпрыска подчеркивается выбором мистического локуса сада, пестрящего бесконечными аллеями и лабиринтами искусственного парка, устроенного по образцу версальского. Темнота как главный атрибут этого лабиринта кустов и деревьев постоянно акцентируется, тем вызывая ассоциации с миром подсознательного. Локус нисхождения (катабасиса), тартар появляется в финале 1-ой книги, метеорологические явления сигнализируют воцарение «тьмы подземелья» (МЕРЕЖКОВСКИЙ 1990: 304), соотносимой со статусом слепоты, участью Эдипа. Царевич в этом «вавилоне» из растений неустанно старается избежать встречи с отцом, как будто он страшится его как нещадного, страшного чудовища. В этом месте 
Алексей невольно оказывается в роли Тесея, которому предстоит совершить подвиг через умерщвление Минотавра, требующего от народа множества жертв. В силу ассоциированности образа царевича с мифологическим персонажем Тесеем, он наделяется не только семантикой «победителя антихриста, мрака, врага общества», но также божественного младенца, filius regis в соответствии с тесаурусом богословия и средневековой философской алхимии. Через ввод мотива лабиринта в ткань романа, с другой стороны, контаминируются мифологемы об Эдипе, убившем собственного отца, и Тесее, покорившем зверские силы, чтобы выполнить моральный долг и через акт инициации обрести гармонию тела и души ${ }^{9}$. Подчеркнем, что сюжетная ситуация в мифологемах об Эдипе и Тесее точка в точку совпадает: героям надо освободить народ от чудовища, жадно домогающегося бесконечных жертв ${ }^{10}$. В случае Эдипа цель достигается способом разгадывания загадки Сфинкса, иначе говоря, поединок должен состояться на уровне символическом, т.е. вербальном: разгадка, ответ Сфинксу именно «человек» (DETHLEFSEN 1990: 25-29). Однако, герой романа Антихрист, повествующего о вечном и длительном поединке отца и сына, если даже осознает значимость своей миссии, неспособен к акту отцеубийства, ибо христианская его религиозность парадоксально сливается со свойственным конфликтом индивидуального типа. В романе же прослеживается вывернутый сюжет мифологемы об Эдипе, ибо погибает не отец, а сын. Эти мифологемы, соотносимые с путем индивидуации, представляют собою два пути становления личности: эдипов миф скорее центрирован на психике индивида ${ }^{11}$, тогда как история

\footnotetext{
${ }^{9} \mathrm{O}$ том, как нижеизлагаемый комплекс понятий закономерно вступает в диалог с термином Ницше «лабиринтный человек», автору настоящей статьи довелось высказаться на юбилейной конференции «Д.С. Мережковский: писатель - критик - богослов», проходившей 8-9 декабря 2016 г. в ИМЛИ РАН и Доме А.Ф. Лосева. Тема «лабиринтного человека» как феномена Серебряного века впервые поднята в работе К.Г. Исупова (ИСУПОВ 2010).

10 Об импликациях мифологемы о Тесее в первой части «египетской дилогии» Мережковского см. (JÓZSA 2016).

${ }^{11}$ По поводу дилеммы индивидуализма даже в узких рамках настоящей работы нам не обойтись без критической переоценки некоторых аналогий философии Ницше с кругом идей, интриговавших Фрейда. Как П.-Л. Ассун суммирует, в конечном итоге, как у Ницше, так и у Фрейда неправильно интерпретируемые силы «биения песни жизни» разрушают право «я». Низвержение высокого идеала достоинств личности наличествует в сходных по сути системах. Исследователь поэтому озадачен вопросом: не становится ли «мыслитель Эроса», защищающий «оскорбленное либидо», «эхом певца Диониса», не очевидно ли, что они оба блуждают «в лабиринте подсознательного и сновидений человека?» [все курсивы здесь и в дальнейшем мои - Д.3. Й.] Расхождения Ницше и Фрейда, попытавшихся разгадывать те же загадки, можно узреть на «перепутье
} 
о Тесее преимущественно касается судьбы индивида, немыслимой вне рамок коллектива.

На парадигму конфликта вечно сменяющихся поколений тенденциозно указывается в том числе и приемом акцентировки имен и отчеств господствующей царской династии: если отчество Петра Великого Алексеевич, - предопределяет имя сына, Алексея Петровича, то новорожденный от жены Шарлотты сын царевича получает в крещении имя Петр, итак замыкается круг. Подчеркиванием данной закономерности тематизируется бесконечный круговорот столкновения поколений отцов и сыновей. Одновременно в выкристаллизованном виде улавливается концепция т. н. «метаисторизма», столь характерного и для Мережковского, и для других русских символистов, в исторической эпике которых конкретные события перемещаются в сферу вечности, подчиняясь единым законам доисторических и трансцендентных схем.

Некоторые элементы Эдиповой ситуации многократно разыгрываются на уровне сюжета: напр. в мотиве оторванности Алексея от матери, заточенной в монастыре; запрет на встречу с матерью висит в воздухе вроде страшного табу, зиждимого по велению Петра, всемогущего отца. Общение с матерью возможно лишь через письма, получаемые царевичем от посредницы, царевны Марьи Алексеевны. Царевна дает царевичу знать, что его личная судьба зависит от «совершения», из ее слов явствует, что речь идет о смерти отца. Марья Алексеевна недвусмысленно повторяет: «Государь ведь человек не бессмертен: воля Божья придет умрет» (МЕРЕЖКОВСКИЙ 1990: 386). Во время визита в покои царевны Марфы Матвеевны, помешавшейся в уме (следовательно, как и другие «юродивые» персонажи, она имеет способность выявлять истину), царевич услышит подобное суждение из уст оторванной от жизни старухи: царевна, вроде ощущая Эдипову ситуацию, обращается к нему как «Сиротинка ты мой бедненький! Ни отца, ни матери». (МЕРЕЖКОВСКИЙ 1990: 389) и прямо называет Петра Антихристом. Практически она совершает оговорку по Фрейду, т.е. подобно психоаналитической ситуации, оказываясь в роли неуклюжего терапевта, невольно высказывается о желании царевича. В результате царевич осознает, что не только его собственная судьба, но также и будущность отечества зависит от истребления отца. Умерщвление отца становится необходимо как залог предотвращения надвигающейся катастрофы,

мифическом (Эдиповом)» - подчеркивает автор (ASSOUN 1994: 126-127). Хотя фрейдовская практика психоанализа, берущая свое начало в теории об Эдиповом комплексе, по меткому замечанию Детлефсена сосредоточена на конфликтах индивидуального типа, на самом деле в процессе глубинного погружения в сферу подсознательного чаще всего занимается сферой безличного. По сущности своей это «безличное», - как автор в дальнейшем уточняет, - есть не что иное, как «архетипичное» (DETHLEFSEN 1990: 25-29). 
угрожающей России. Можно прийти к выводу, что Алексей сталкивается лицом к лицу с романтическим и трагическим конфликтом, где оба выбора приводят к крушению. Христианское смирение исключает роль победоносца, трагический опыт русской истории непременно придает акту цареубийства оттенок ереси самозванства. Столкновение с отцом в Летнем саду - другой эпизод, пестрящий тонкими сексуальными коннотациями: царевич, бежавший от отца, презирает себя за заячью «трусливость» «невольного движения» («Будто заяц в кусты шмыгнул». (МЕРЕЖКОВСКИЙ 1990: 331)). Как общеизвестно, символ животного включает в себя и семантику половых, зарождающих энергий. А последующий за этой встречей разговор с Абрамовым опять-таки зайдет об «Овидиевых и Вергилиевых книжницах», чем делается намек на круг тех мифологических источников, в освещении которых произошедшее приобретет иную интерпретацию, и события как бы перемещаются в давно забытую атмосферу, характерную для сознания древнего человека. При второй «лабиринтной» встрече (ведь тропинка узка для двоих) глаза царя предстают как символ ясновидения, органа восприятия света, но одновременно актуализируют мысль о кардинальном элементе мифологемы об Эдипе, лишившего себя зрения, тем самым воспроизводят архетипическую ситуацию. В силовом поле таких коннотаций, понимаемых в динамике синхронии и диахронии чувств и мыслей авторефлексирующего Алексея, глаза царя связаны с сыновним чувством любви к отцу и памятью о детской беззащитности, однако, эксплицитно снабжены и коннотациями, указывающими на сложный процесс полового развития и на концепцию Мережковского об андрогинности: они - «такие милые, что когда-то они снились ему, как снятся влюбленному отроку глаза прекрасной женщины» (МЕРЕЖКОВСКИЙ 1990: 332). Мотив желания убить отца, амбивалентно мучащего сына, сильно акцентирован. Весть о предсмертном причащении больного царя позволяет Алексею понять «как близко то, что всегда казалось ему далеким, почти невозможным. Сердце у него упало, дух захватило, он сам не знал отчего, - от радости или ужаса» (МЕРЕЖКОВСКИЙ 1990: 474). Последующие упреки архимандрита Федоса подтверждают его ожидания, архиерей целует царевичу руку в знак того, что он признает его «самодержцем всероссийским», и «в мыслях его» узнавал царевич «свои собственные, тайные, злые мысли об отце». После разговора, преисполненного драматического напряжения «игры кошки мышки», царевич увидел при свете свечки то «отчего ему было так весело - надежду, что отец умрет». На исповедании Алексей «духовному отиу» протопопу Якову признается в том, что отцу своему «смерти желал», а тот его утешает словами: «Бог тебе простит, чадо. Мы и все ему желаем смерти» (МЕРЕЖКОВСКИЙ 1990: 480-481).

О том, что мифологему об Эдипе Мережковский досконально штудировал, свидетельствует его уникальный интерес, питаемый к 
трагедиям Софокла, которого Детлефсен недаром называет «бойцом против секуляризации». Исследователь в контексте интерпретации мифологемы об Эдипе определяет жанр трагедии как культовое действо, и обращает внимание на то, что действующее лицо в трагедии всегда герой или король, который посвящает себя высшим задачам человеческого бытия, т.е. "решает стать на пути индивидуации», поэтому он готов принимать истину (DETHLEFSEN 1990: 63). Открывающий новые горизонты ключ к расшифровке мифологизированной и до невозможности банализованной в начале XX века фигуры Эдипа оказывается применимым для разбора романа Мережковского. За работу над переводом Царя Эдипа и Эдипа в Колоне Мережковский берется кстати в период 1894-1896 гг., во время кульминации влияния на него учений Ницше, во многом определившего русское сознание рубежа двух столетий ${ }^{12}$. Восторг от чтения произведений Ницше для него симультанно означает обострение дилеммы между индивидуализмом и традиционным для русской православной культуры коллективизмом, сочетающимся с императивом смирения. Симпатизировавший идеям Ницше о культе красоты, его отказу от традиционных христианских ценностей альтруизма, аскетизма и смирения, Мережковский высоко ценит Рождение трагедии из духа музыки в ракурсе как интерпретации двух русел европейской культуры, так и восприятия «вечных форм» (ROSENTHAL 1986: 69-70, 72). Он чуть ли не обожествляет фигуру Заратустры, как предтечу «нового человека», предвещающего собственный идеал достижения гармоничного равновесия между двумя началами европейской культуры, - эллинским и христианским. Вовсе неслучайно, что Мережковский наталкивается на образ Заратустры как на ключевую фигуру, обладающую потенциалом разрешить судьбы России. Данная идея сочетается с проблемой Востока и Запада, унаследованной по преимуществу собственно от Петра Великого. В размышлениях Мережковского о сверхчеловеке, стимулированных фигурой Заратустры, Петр I выступает как русский вариант данного типа. Мысль об этом встречается в трактате Л. Толстой и Достоевский (19011902), увидевшем свет намного раньше, чем роман Петр и Алексей: «Особый поразительный смысл имеет для нас, русских, явление Заратустры и потому, что мы принадлежим к народу, который дал миру, может быть, единственное величайшее во всей новой европейской истории воплощение сверхчеловеческой воли - в Петре. Религиозная часть русского народа сложила странную и доныне мало исследованную легенду о Петре как об Антихристе, об апокалиптическом "Звере, вышедшем из бездны"» (МЕРЕЖКОВСКИЙ 1995: 9).

12 Литературу об этом см. в монографии венгерского блоковеда М. Дьендьеши (GYÖNGYÖSI 2004: 87-107), и сборнике работ, составленном Б. Розенталь (ROSENTHAL 1986). 
В данном трактате подчеркивается весомость драматического характера романов и словесного таланта Достоевского, а сам романист не только уподобляется «творцу Эдипа» (МЕРЕЖКОВСКИЙ 1995: 110). Позиция Мережковского насчет мирового призвания русской словесности конкретизируется в контексте трактовки фрагмента о «всех мировых противоречиях», выделенного им из Пушкинской речи Достоевского: Мережковский возвышает феномен Пушкина, эксплицитно апеллируя именно к образу Эдипа, как к эквиваленту заблудившегося современного человека, жаждущего перерождения. Чтобы по-настоящему оценить духовную устремленность русской литературы, следует лишь обратиться к ее зачинателю, Пушкину: «Загадка Пушкина стоит на всех путях нового русского сознания, как загадка Сфинкса перед Эдипом» (МЕРЕЖКОВСКИЙ 1995: 11). Иначе говоря, прототипом богоищущего адепта является Эдип, и апокалипсические ожидания начала века, эсхатологическая ориентированность русской литературы и свершение преображения мира способом теургического акта приравниваются переживанию и решению Эдиповой ситуации.

\section{Литература}

ГРОЙС 1989 = ГРОЙС Б. Россия как подсознание Запада. // Wiener Slawistischer Almanach, 1989, (Band 23), 199-213.

ИСУПОВ $2010=$ ИСУПОВ К.Г. Путь в лабиринте. // Исупов К.Г. Судьбы классического наследия и философско-эстетическая культура Серебряного века. Санкт-Петербург 2010, 421-437.

ЛАВРОВ $2000=$ ЛАВРОВ А. История как мистерия: Египетская дилогия Д. С. Мережковского // Мережковский, Дмитрий. Мессия (Вст. ст. А.В. Лаврова). Санкт-Петербург, 2000. 5-27.

МЕРЕЖКОВСКИЙ 1972 = МЕРЕЖКОВСКИЙ Д.С. Избранные статьи. München, 1971.

МЕРЕЖКОВСКИЙ $1990=$ МЕРЕЖКОВСКИЙ Д.С. Петр и Алексей // Мережковский Д.С. Собр. соч. в 4 тт. Т. 2. Москва, 1990. 319-759.

МЕРЕЖКОВСКИЙ 1995 = МЕРЕЖКОВСКИЙ Д.С. Л. Толстой и Достоевский. Москва, 1995.

РЫЧКОВ 2010 = РЫЧКОВ А. Д.С. Мережковский и К.Г. Юнг. «Встреча во гнозисе» // Судьбы литературы Серебряного века и русского зарубежья (отв. ред. Аверин Б.В., Валчева Ю.М.). Санкт-Петербург, 2010. 202-211.

ЮНГ 1996 = ЮНГ К.Г. Собрание сочинений. Дух Меркурий. Москва, 1996.

ЭТКИНД 1993 = ЭТКИНД А.М. Эрос невозможного. История психоанализа в России. Санкт-Петербург, 1993.

ASSOUN 1994 = ASSOUN P-L. A pszichoanalízis öröksége // Ex-Symposium, 1994, Nietzsche-különszám, 126-127.

ASSOUN 2002 = ASSOUN P.-L. Freud and Nietzsche. London - New York, 2002.

BISHOP 1995 = BISHOP P. The Dionysian Self. C.G. Jung's Reception of Friedrich Nietzsche. Berlin-New York, 1995. 
DETHLEFSEN 1990 = DETHLEFSEN TH. Oidipusz, a talány megfejtője [Ödipus der Rätsellöser]. Budapest, 1990.

GYÖNGYÖSI 2004 = GYÖNGYÖSI M. Александр Блок и немецкая культура. Frankfurt am Main et al. 2004.

JONES 1963 = JONES E. The Life and Work of Sigmund Freud. Garden City N.Y. 1963.

JÓZSA 2016 = JÓZSA GY.Z. Миф и инициация: К проблеме «полижанровости» романа Мережковского «Рождение богов. Тутанкамон на Крите» // Toronto Slavic Quarterly, 2016, №57 (summer). 122-142.

LJUNGGREN 1994 = LJUNGGREN M. The Russian Mephisto. A Study of the Life and Work of Emilij Medtner. Stockholm, 1994.

МЕТНЕР 2013 = МЕТНЕР Э.К. О юнговской психологии. Ижевск, 2013.

ROSENTHAL 1986 = ROSENTHAL B.G. Stages of Nietzscheanism. Merezhkovsky's Intellectual Evolution // Nietzsche in Russia (ed. Rosenthal B.G.). Princeton, 1986.

SZILÁRD - JÓZSA 1996 = SZILÁRD L. - JÓZSA GY.Z. Andrej Belij Pétervár // Huszonöt fontos orosz regény (szerk. Hetényi Zs.). Budapest, 1996. 134-149. 